\title{
Combined Antiretroviral Therapy (cART) Reduces AIDS-Related and Non- AIDS-Related Mortality: A Temporal Analysis from Time of Seroconversion (SC)
}

Maria Dorrucci ${ }^{1}$, Luca Colarusso ${ }^{2}$, Vincenza Regine ${ }^{3}$, Simona Di Giambenedetto ${ }^{4}$, Giovanni Di Perri ${ }^{5}$ Francesco Castelli $^{6}$, Laura Camoni ${ }^{3}$, Angela Calamo ${ }^{7}$, Massimo Giuliani ${ }^{8}$, Rino Bellocco ${ }^{2,9}$, Francesca Farchi ${ }^{1}$, Mauro Zaccarelli ${ }^{10}$ and Barbara Suligoi ${ }^{3}$

${ }^{1}$ Department of Infectious, Parasitic and Immune-mediated Diseases, Istituto Superiore di Sanità, Rome, Italy

${ }^{2}$ Department of Statistics and Quantitative Methods, University of Milano-Bicocca, Milan, Italy

${ }^{3}$ National AIDS-Unit, Istituto Superiore di Sanità, Rome, Italy

${ }^{4}$ Università Cattolica S. Cuore, Rome, Italy

5 Infectious Diseases, University of Turin, Italy

${ }^{6}$ Spedali Civili, Brescia, Italy

${ }^{7}$ Malattie Infettive, Policlinico di Bari, Italy

${ }^{8}$ San Gallicano Dermatological Institute, Rome, Italy

${ }^{9}$ Department of Medical Epidemiology and Biostatistics, Karolinska Institutet, Stockholm, Sweden

${ }^{10}$ National Institute for Infectious Diseases “Lazzaro Spallanzani”, Rome, Italy

\begin{abstract}
Objectives: To estimate changes of AIDS and non-AIDS mortalities from 1996 to 2010 comparing (2004-2010) vs. (1996-2003) periods from the time of HIV-seroconversion (SC).
\end{abstract}

Methods: Data derived from an Italian multicentre prospective and open cohort; competing risks approach was applied estimating the cumulative incidence functions (CIF) for AIDS and non-AIDS deaths over time from SC with delayed entries in the two cART periods. Cox-cause-specific hazards models were applied to estimate relative hazards $(\mathrm{RH})$ of AIDS and non-AIDS related deaths.

Results: Of 2,249 individuals with known SC date followed from SC and from January 1996 to December 2010, 1,779 were survived, seroconverted or followed during 1996-2003, while 1,715 during 2004-2010. A total of 278 deaths occurred from 1996 to 2010: 197 in the early years of cART [61 (31\%) non-AIDS deaths], and 81 during more recent cART period [48 (59\%) non-AIDS deaths].

The CIF of AIDS related deaths was higher than CIF of non-AIDS related deaths in the early period [for instance, estimates at $15 \mathrm{yrs}$ from SC: CIF of AIDS-related death $=0.15(95 \% \mathrm{Cl}: 0.12-0.19)$ and CIF of non-AIDS related $=0.09$ (95\% Cl: 0.07-0.12)], whilst in 2004-2010 period the CIF of non-AIDS related deaths was slightly higher [estimates at 15 yrs from SC: CIF of non-AIDS related $=0.03(95 \% \mathrm{Cl}: 0.02-0.04)$ vs. CIF of AIDS-related death $=0.02(95 \% \mathrm{Cl}$ : 0.02-0.04)]. Comparing the two periods by Cox proportional-cause-specific models, the hazard was lower for AIDS deaths than for non-AIDS related deaths [RH of non-AIDS deaths from last viral load $(\mathrm{VL})<200 \mathrm{copies} / \mathrm{mL}$ was 0.60 $(95 \% \mathrm{Cl}(0.35-1.03)]$, while of AIDS-deaths was 0.32 (95\% Cl: $0.17-0.62)$, both RH relative to (2004-2010) vs. (19962003)].

Conclusions: Considering early years of the cART period as a reference, we observed a decrease in both AIDS and non-AIDS-mortalities. In more recent CART years, non-AIDS mortality tended to decline less than AIDS-relatedmortality since HIV-SC, even after effective CART.

Keywords: HIV-seroconversion; Prospective study; AIDS and nonAIDS related mortalities; cART (combination Antiretroviral Therapy); Competing risks

\section{Introduction}

In recent years, mortality for people living with HIV has dramatically decreased. The reason for such decreasing trend is inextricably related to the introduction in the middle of 1996 of the combination antiretroviral therapy (cART) that allowed life expectancy of HIV-infected individuals to approach that of the general population when successfully treated [1].

As a consequence of such life expectancy prolongation, HIVinfected people are more likely to die from non-HIV related causes. By living longer they are more exposed to other non-AIDS related conditions such as: ageing and related co-morbidities, cardiovascular diseases (CVD), cancers, and other viral infections such as viral hepatitis $\mathrm{B}(\mathrm{HBV})$ and $\mathrm{C}(\mathrm{HCV})$. The relevance of these non-AIDS related conditions is increasing especially in high-income countries: an excess of mortality from cancer [2-4] and CVD [1] has been reported; chronic infections due to HCV [5] or HBV [6] appear to accelerate the progression of liver disease and increase mortality in HIV-infected individuals. Furthermore, the prolonged exposure to cART regimen can lead to an increased risk of dying from therapy-related toxicities.

*Corresponding author: Vincenza Regine, National AIDS-Unit, Istituto Superiore di Sanità, Rome, Italy, Tel: 390649902273; E-mail: vincenza.regine@iss.it

Received September 25, 2015; Accepted Novmeber 20, 2015; Published November 26, 2015

Citation: Dorrucci M, Colarusso L, Regine V, Giambenedetto SD, Perri GD, et al (2015) Combined Antiretroviral Therapy (cART) Reduces AIDS-Related and NonAIDS-Related Mortality: A Temporal Analysis from Time of Seroconversion (SC). J AIDS Clin Res 6: 523. doi:10.4172/2155-6113.1000523

Copyright: (c) 2015 Dorrucci M, et al. This is an open-access article distributed under the terms of the Creative Commons Attribution License, which permits unrestricted use, distribution, and reproduction in any medium, provided the original author and source are credited. 
Recent studies investigated trends in causes of death in HIVpositive populations showing that overall mortality, primarily AIDSrelated mortality, continuously decreased over time [7-9]. However, no study has evaluated the trend in mortality taking into consideration the duration of HIV infection, i.e., since the estimated date of seroconversion. This allows to perform estimates among those who have had their HIV-diagnosis early, so have the best chances of access to treatment, while the prevalent cohorts could include patients who start therapy later because of late HIV-diagnosis.

We investigated the change over time of AIDS and non-AIDS related deaths and the association with some demographic and clinical characteristics comparing two post-cART periods (1996-2003 and 2004-2010) in an Italian cohort [Italian HIV-seroconversion study (ISS)] composed of individuals followed since the estimated date of SC.

\section{Methods}

\section{Study population}

Study population includes individuals enrolled in the ISS cohort that is an open, multicenter (18 infectious disease clinics throughout Italy), prospective, incident cohort established in Italy in 1987. Details of this cohort have been described elsewhere $[10,11]$.

Briefly, individual data are collected at clinical sites, extracted electronically from clinical and laboratory data files and sent to the coordinating center (Istituto Superiore di Sanità, the Italian National Institute of Health) approximately every 6 months. Prerequisite to be enrolled in the cohort was the availability of an HIV-negative test followed by an HIV-positive test. The date of seroconversion (SC), estimated as the midpoint of the dates of the two tests, was considered as the starting point in time for all survival-related analyses.

Reference clinicians participating in the cohort study provided anonymous individual data on a predefined set of demographic, laboratory, and clinical variables, including age, sex, exposure-category HCV serostatus, cART regimen, CD4+ and CD8+ cell counts, HIV-1 viral load; HCV positivity was defined as the detection of anti-HCV antibodies and/or HCV-RNA.

The study included individuals enrolled between 1987 and 2010. Participants died for unknown causes or died in the pre-1996 period were excluded from analysis. The patients with unknown cause were excluded after verifying that main results did not change by including them as an additional end-point.

For sensitivity analyses we analyzed subsets of the study population who fulfilled specific criteria, as described in detail later.

\section{Follow-up}

Participants were followed from the estimated date of SC until either the date of death, or loss to follow-up, or established censoring date for ascertaining events (i.e., December 31, 2010), whichever occurred first.

To assess trends in overall and cause-specific mortality, the follow-up period was divided into two calendar periods, 1996-2003 and 2004-2010, defined as early and recent cART period, respectively. We chose these two calendar periods when observing that from 1996 to 2010 a decreasing trend over 2 calendar yrs intervals of both AIDS and non AIDSmortalities rates were observed. After 2004 two new classes of ART drugs were introduced in Western countries, i.e., fusion and entry inhibitors that could have had an impact on increased survival. Total person-years, therefore, (i.e., the number of years each individual contributes during follow-up) were estimated for the two calendar periods.
Information on causes of death were obtained from reference ISS cohort clinicians. In particular, clinicians were requested to state in the death certificate the immediate cause, the contributing cause, and the underlying cause of death [10]. Further, the validity of causes reported by cohort clinicians were checked both in the National AIDS registry [12] and/or in the official-local death registries and coded (by clinicians of the study cohort) according to ICD-9 or the ICD-10 [13] depending on when death occurred.

For the analyses deaths were grouped as AIDS and non-AIDSrelated deaths. And non-AIDS deaths were classified as cardiovascular disease-related, hepatitis-related, non-AIDS cancer and other.

\section{Statistical analysis}

We applied a competing risks approach, i.e., one of the statistical methods used when an individual is at risk of more than one type of event [14]. In the present study, enrolled individuals were at risk of dying from various diseases and deaths were grouped, for simplicity, as AIDS or non-AIDS-related deaths. In the above-mentioned context, we estimated the cumulative incidence function (CIF) as a measure of competing-risk death, and Cox-cause-specific models. We chose to apply Cox-cause-specific models assuming that the underlying cause of death was accurately recorded by clinicians.

CIF of AIDS and non-AIDS related deaths was estimated and plotted for the two selected calendar periods, controlling for staggered entries in both periods from SC date. We estimated also relative hazards (RH) and 95\% Confidence Interval (CI) for AIDS and non-AIDS mortality by Cox-cause-specific models [14]. The variable of interest in these Cox models was calendar period entered as a dichotomous-timedependent covariate (i.e., 2004-2010 vs. 1996-2003); the time zero of all Cox models was the estimate date of SC. Cox models were stratified by gender, HCV serostatus (positive vs. negative), exposure-category: injecting drug users (IDUs), men who have sex with men (MSM), heterosexuals, and not determined. Due to the importance of ageing, the variable age was considered as the time scale instead of time from SC. The latter, in brief, was an alternative way of controlling for age in order to explicit the ageing effect $[15,16]$.

High CD4 count $\left(>500\right.$ cells $\left./ \mathrm{mm}^{3}\right)$ or low viral load (VL) $(<200$ copies $/ \mathrm{ml}$ ) observed after cART initiation were considered as indicators of effective antiviral treatment. These variables were analyzed to assess associations between effective cART and survival. To this aim, lefttruncation was applied from SC at selected visits with last CD $4 \geq 500$, cells $/ \mathrm{mm}^{3}$ or last HIV-load $<200$ after start of cART. In these cases only follow-up after the above mentioned dates were considered, i.e., only the survival experiences after these dates (last CD $4 \geq 500$, cells/ $\mathrm{mm}^{3}$ or last HIV-load $<200$ ) were included in the analysis. Of note, to account for possible immortal time-bias, all estimates (CIF graphs and $\mathrm{RHs}$ ) were performed considering for each individual delayed entries in each calendar period from SC, in other terms, considering the different survival times from SC to the beginning of each calendar period.

\section{Ethics}

The study was approved by the "Comitato Etico dell'Istituto Superiore di Sanità" (National committee for ethics of bio-medical studies in Italy).

\section{Results}

\section{Recruited patients in the ISS cohort}

A total of 3,031 adults were enrolled and followed in the ISS study 
Citation: Dorrucci M, Colarusso L, Regine V, Giambenedetto SD, Perri GD, et al. (2015) Combined Antiretroviral Therapy (cART) Reduces AIDS-Related and Non-AIDS-Related Mortality: A Temporal Analysis from Time of Seroconversion (SC). J AIDS Clin Res 6: 523. doi:10.4172/21556113.1000523

Page 3 of 8

from 1987 to 2010 . The median interval between last-HIV negative and first HIV-positive dates was 0.7 yrs with IQR: 0.4-1.1 yrs. We excluded $180(6 \%)$ patients with an interval of SC $>3$ yrs (median 5 yrs, IQR: 4-6 yrs, range: 3-22 yrs), and we further excluded 541 and 61 patients (because of unknown causes of death, as mentioned in the inclusion criteria in study population paragraph [the majority $(18 \%)$ because died before 1996, Fluxogram 1].

The selected population of 2,249 individuals was followed for 24,043 person-years of follow-up, during whom a total of 43,394 visits were performed (median number of visits: 14; IQR: 7-28). Of note, the period of interest included a total of 17,230 person-years, i.e. from 1996 to 2010 (Fluxogram 2).

\section{Descriptive of the selected population in the two periods}

We analyzed 2,249 HIV-infected patients. Most of them started cART during follow-up (1,915 patients, $86 \%)$. The general characteristics of the patients for the early (1996-2003) and recent (2004-2010) cART periods are shown in Table 1:1,779 patients were followed in early cART period with 8,768 person-years estimated for the early cART period. Of these, 560 (31\%) were new SC (seroconversions) diagnosed in that period. During more recent cART period, 1,715 patient were followed with 8,462 person-years of follow-up, of these 370 (22\%) were new SC. Compared with patients in the early cART period, seroconversion in the recent cART period occurred at little more old age ( $30 \mathrm{vs.} 28$ years).

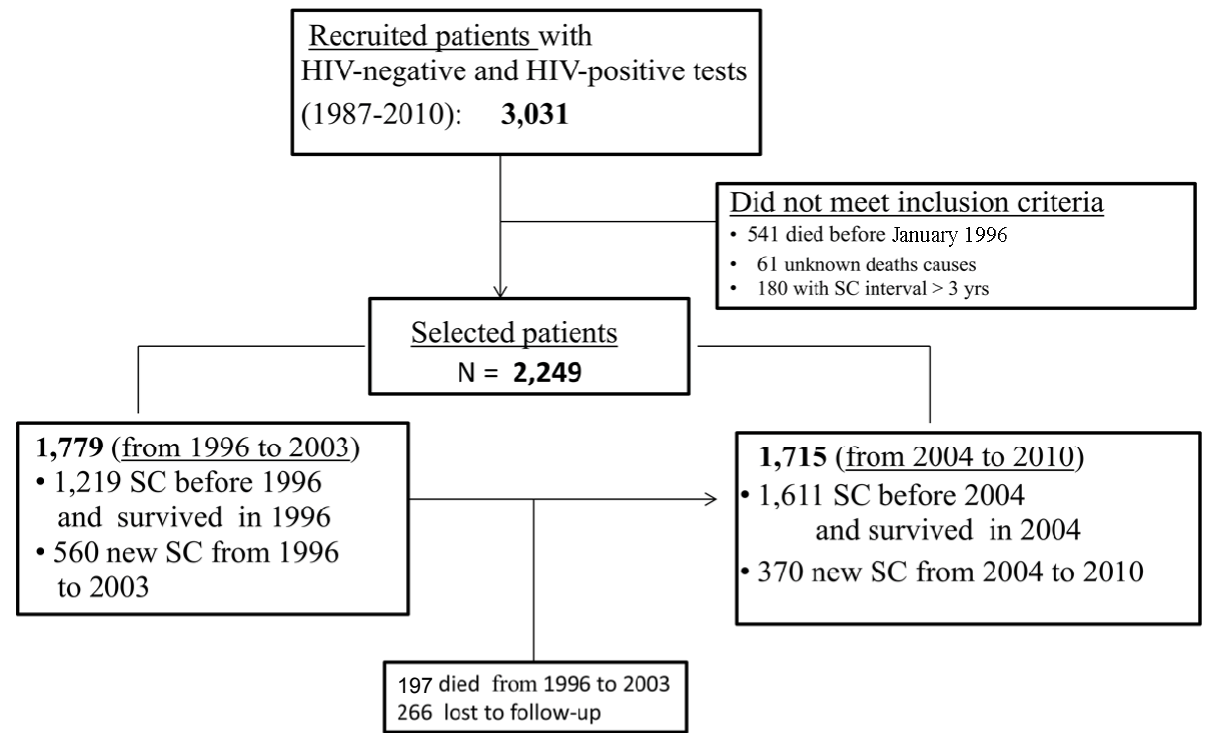

Fluxogram 1: Dynamics of the ISS cohort: a) excluded and included patients from the initial cohort; b) individuation of the studied groups by the two calendar periods of interest; SC: seroconversion for HIV

Total person-years from SC

of those included in the study, thus survived in 1996

$\mathbf{2 4 , 0 4 3}$ person-years

6,813 person years excluded from 1987 to the end of 1995 according to the studied periods

$\mathbf{8 , 7 6 8}$ person years

from 1996 to 2010

(summing yrs of follow-up

in first cART period) $\mathbf{8 , 4 6 2}$ person years

from 2004 to 2010

(summing yrs of follow-up

in second cART period)

Fluxogram 2: Estimates of person-years according to calendar periods in the ISS cohort. 
Citation: Dorrucci M, Colarusso L, Regine V, Giambenedetto SD, Perri GD, et al. (2015) Combined Antiretroviral Therapy (cART) Reduces AIDS-Related and Non-AIDS-Related Mortality: A Temporal Analysis from Time of Seroconversion (SC). J AIDS Clin Res 6: 523. doi:10.4172/21556113.1000523

Page 4 of 8

\begin{tabular}{|c|c|c|}
\hline & \multicolumn{2}{|c|}{ Calendar periods } \\
\hline & $(1996-2003)$ & $(2004-2010)$ \\
\hline & 1,779 patients & 1,715 patients \\
\hline & 8,768 person-years & 8,462 person-years \\
\hline Males & $1,205(68 \%)$ & $1,246(73 \%)$ \\
\hline $\mathrm{Age}^{1}$ at SC & $28(24-34)$ & $30(25-36)$ \\
\hline \multicolumn{3}{|l|}{ HIV-Exposed through } \\
\hline Injecting Drug Use (IDU) & $712(40 \%)$ & $514(30 \%)$ \\
\hline Sex between Men (MSM) & $516(29 \%)$ & $583(34 \%)$ \\
\hline Sex between Heterosexuals & $360(20 \%)$ & $377(22 \%)$ \\
\hline Other ${ }^{2}$ or unknown & $196(11 \%)$ & $240(14 \%)$ \\
\hline Year of HIV-seroconversion ${ }^{1}$ & $1993(1989-1997)$ & $1996(1992-2004)$ \\
\hline HCV-positive ${ }^{3}$ & $54 \%$ & $41 \%$ \\
\hline \multicolumn{3}{|l|}{ Proportion of time on: } \\
\hline $\mathrm{cART}^{4}$ & $48 \%$ & $86 \%$ \\
\hline$N R T I^{5}$ & $84 \%$ & $62 \%$ \\
\hline $\mathrm{NNRTI}^{5}$ & $44 \%$ & $87 \%$ \\
\hline $\mathrm{Pl}^{5}$ & $70 \%$ & $85 \%$ \\
\hline Fusion inhibitors ${ }^{5}$ & - & $42 \%$ \\
\hline CCR5 - inhibitors ${ }^{5}$ & - & $11 \%$ \\
\hline
\end{tabular}

${ }^{1}$ values for continuous variables are expressed as median values and inter-quartile ranges;

${ }^{2}$ other: hemophiliac, blood/tissue recipient non-hemophiliac;

${ }^{3}$ data available on $70 \%$ of the studied population;

${ }^{4}$ proportion, $\%$ = number of person-years on $\mathrm{CART} /$ number of person-years within the period;

${ }^{5}$ proportion, $\%=$ number of person-years on specific cART regimen / number of person-years on CART.

SC: seroconversion for HIV.

Table 1: Characteristics of the Italian HIV-Seroconversion Study by early and more recent CART period.

The proportion of males tended slightly to increase from early to recent cART period ( $48 \%$ vs. $86 \%$, respectively) as well as the proportion of men who have sex with men (MSM) resulted higher from early to recent CART period, whereas the proportion of injecting drug users (IDU) decreased. The proportion of heterosexuals slightly increased. The proportion of HCV-HIV co-infected was higher in the first period than in that after (54\% vs. $41 \%)$.

Further, the proportion of total person-years (on the total personyears of the period) spent on cART was higher during (2004-2010) vs. (1996-2003), (48\% vs. $86 \%)$.

\section{Causes of death}

During follow-up, 278 deaths were identified (197 (71\% of total occurred deaths; and 81 (29\%) in more recent cART period).

In Table 2 are shown specific causes of AIDS-related death and nonAIDS-related deaths.

Incidence Rates of more common mentioned causes of death observed in the both periods are shown in Table 3. Comparing the two calendar periods the IR of all grouped causes of death was lower in the more recent period, whereas the IR of non-AIDS cancers was stable.

\section{CD4 and VL one year before death}

CD4 cell count within one year before death for both early and more recent CART period was graphically summarized in Figure 1: median CD4 cell count before death resulted for all causes higher in more recent period vs. early cART period (medians and interqurtile ranges (IQR) from 2004 to 2010: 421 (IQR: 264-621) and 331 (IQR:179-509) IQR; p-value $<=0.001)$. In particular, it resulted higher for non-AIDS causes

in both periods (median CD4 cell count 303 (IQR: 169-493) in early cART period and median CD4 equals to 372 (IQR: 227-555) in recent cART period; $p$-value for difference $\leq 0.01$ ). Inversely, VL (expressed as Log10 copies/ml) resulted lower in recent cART period for all causes of death, especially in the case of non-AIDS causes (median viral load

\begin{tabular}{|c|c|c|}
\hline & early cART & more recent cART \\
\hline & $(1996-2003)$ & $(2004-2010)$ \\
\hline All deaths: $\mathbf{n}$ ( $\%$ row) & $197(71 \%)$ & $81(29 \%)$ \\
\hline AIDS-related deaths $(n, \%)$ : & 136 & 33 \\
\hline Esophageal candidiasis & $13(11 \%)$ & $7(21 \%)$ \\
\hline Non-Hodgkin's Lymphoma & $13(11 \%)$ & $1(3 \%)$ \\
\hline Encephalopathy & $10(8 \%)$ & $2(6 \%)$ \\
\hline Pneumocystis carinii Pneumonia & $6(5 \%)$ & $1(3 \%)$ \\
\hline HIV wasting syndrome & $3(2 \%)$ & $3(9 \%)$ \\
\hline Unspecified AIDS/Other ${ }^{1}$ & $91(67 \%)$ & $19(58 \%)$ \\
\hline non-AIDS-related-deaths $(\mathrm{n}, \%)$ : & 61 & 48 \\
\hline non-AIDS cancers ${ }^{2}$ & $9(15 \%)$ & $9(19 \%)$ \\
\hline Cardiovascular diseases $^{3}$ & $8(13 \%)$ & $6(12 \%)$ \\
\hline hepatitis-related ${ }^{4}$ & $13(21 \%)$ & $10(21 \%)$ \\
\hline other $^{5}$ & $31(51 \%)$ & $23(48 \%)$ \\
\hline
\end{tabular}

${ }^{1}$ other reported as (AIDS-related) includes: Tuberculosis, Recurrent pneumonia, Cryptococcosis, Burkitt's lymphoma, HIV wasting syndrome, CMV, Other bacterial infections, PML, Multiple Infections, Invasive Cervical Cancer, Progressive multifocal leukoencephalopathy (PML); Unspecified AIDS (70\%).

${ }^{2}$ non-AIDS cancers includes: Malignant neoplasm of pancreas, part unspecified, Secondary malignant neoplasm of other specified sites, Malignant neoplasm of liver, not specified as primary or secondary, Hodjking lymphoma, Malignant neoplasm of stomach, unspecified, Malignant Neoplasm of Cardia, Malignant neoplasm of uterus, part unspecified, Malignant neoplasm of descending colon, Malignant neoplasm of anus, unspecified, Neoplasm of uncertain behavior of other specified sites, Breast Cancer, Malignant neoplasm of unspecified part of bronchus or lung, Malignant neoplasm of liver, not specified as primary or secondary, Other malignant lymphomas;

${ }^{3}$ Cardiovascular-diseases includes: Acute myocardial Infarction, Acute myocardial Infarction Unspecified, Cardiac Arrest, unspecified, Atherosclerotic heart disease of native coronary artery, Stroke, not specified as haemorrhage or infarction, Acute but ill-defined, cerebrovascular disease, Non traumatic intracerebral hemorrhage in cerebellum;

${ }^{4}$ Hepatitis includes: Hepatitis in viral diseases classified elsewhere, Chronic hepatitis, unspecified, Other and unspecified cirrhosis of liver, Acute hepatitis B without delta-agent and without hepatic coma, Other specified viral hepatitis with hepatic coma;

${ }^{5}$ Other: Suicide, Accident, Poisoning by, adverse effect of and underdosing of other and unspecified psychodysleptics, Overdose; renal dysfunction disease; Other chronic obstructive pulmonary disease;

Other interstitial pulmonary diseases; Septicaemia; Bacterial infection of unspecified site.

Table 2. Distribution of AIDS-related and non-AIDS causes of death by studied calendar periods

(Total deaths $=278$ occurred from 1996 to 2010, IQR of seroconversions: (19892004); Italian Seroconversion Study (ISS)).

\begin{tabular}{|r|c|l|}
\hline & $(1996-2003)$ & $(2004-2010)$ \\
\hline All deaths & $\mathrm{n}=197$ & $\mathrm{n}=81$ \\
\hline AIDS-related & $\mathrm{IR}(95 \% \mathrm{CI})$ & $\mathrm{IR}(95 \% \mathrm{CI})$ \\
\hline Non-AIDS-related & $0.55(1.31-1.83)$ & $0.39(0.28-0.55)$ \\
\hline Specific causes of non-AIDS-death: & & $0.57(0.43-0.75)$ \\
\hline non-AIDS cancers & $0.10(0.04-0.18)$ & $0.10(0.05-0.18)$ \\
\hline Cardiovascular diseases & $0.09(0.05-0.18)$ & $0.07(0.03-0.14)$ \\
\hline Hepatitis-related & $0.15(0.09-0.26)$ & $0.12(0.06-0.20)$ \\
\hline Other & $0.35(0.24-0.50)$ & $0.27(0.17-0.41)$ \\
\hline
\end{tabular}

Note: Specific causes of death are mentioned in table 2.

Table 3: Incidence rates (IR) per 100 person-years and $95 \% \mathrm{Cl}$ according to more frequent non-AIDS-related causes of death. 


\section{part a) CD4 cell count within one year before death}

CD4 count at death: 1996-2003

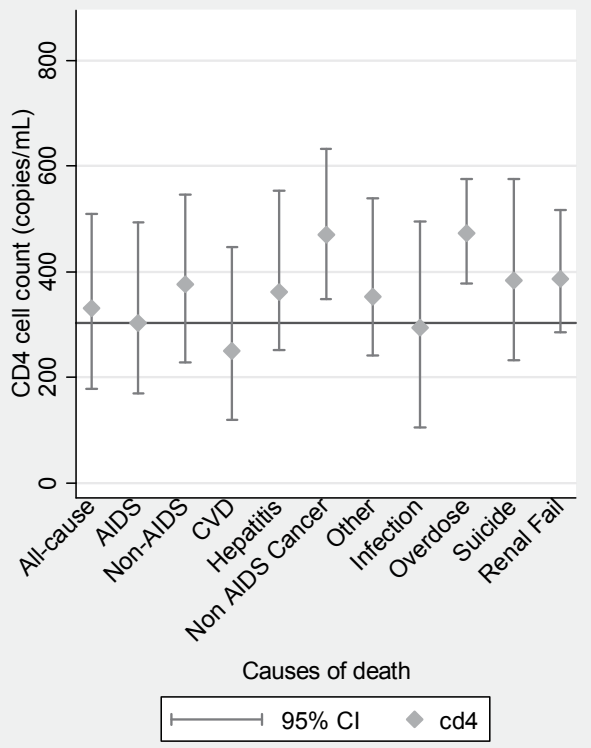

CD4 count at death: $2004-2010$

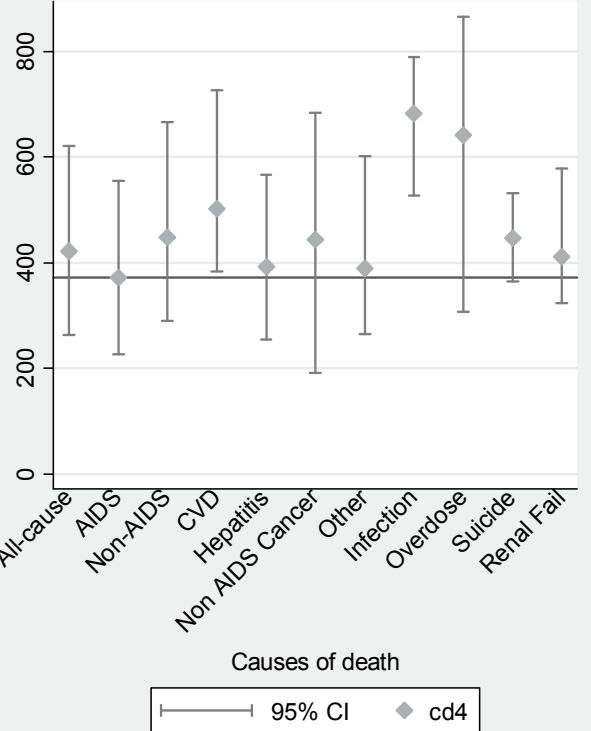

part b)

Viral Load within one year before death

VL count at death: 1996-2003

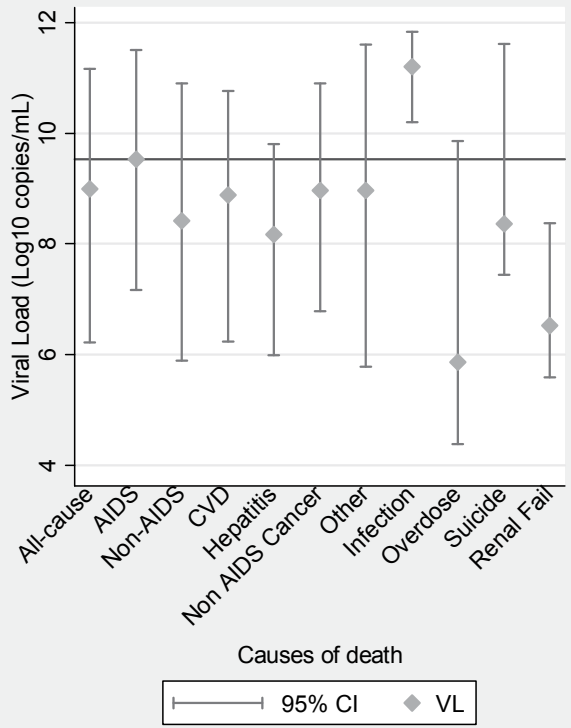

VL count at death: 2004-2010

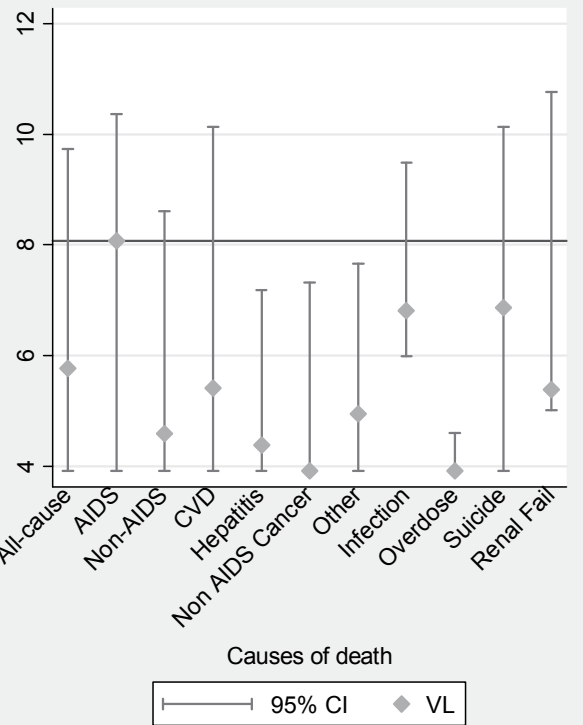

Figure 1: Median CD4 cell count (part a) and median viral load (part b) at death (within one year before death) from all causes of death in early and recent cART period. The horizontal line shows CD4 cell count and viral load for AIDS-related causes of death only.

equals to 8.4 (IQR: $5.9-10.9$ ) in early versus recent period (median VL equals to 4.6 (IQR: 3.9-8.6); p-vale for difference $\leq 0.01$ ).

\section{Cumulative incidences functions of non-AIDS and AIDS death}

Cumulative incidences (CIF) for the two grouped causes of death in the early cART and in more recent cART period are shown in Figure 2. Both CIF of AIDS and non-AIDS death decreased over time from SC according to the two calendar periods; in the last period CIF of non-AIDS related death tended to be slightly higher than AIDS related death (for instance, at 15 yrs from SC cumulative incidence was 0.03 (95\% CI: 0.02 0.04 ) for non-AIDS and 0.02 (95\% CI: 0.02-0.04) for AIDS-related death). 
Citation: Dorrucci M, Colarusso L, Regine V, Giambenedetto SD, Perri GD, et al. (2015) Combined Antiretroviral Therapy (cART) Reduces AIDS-Related and Non-AIDS-Related Mortality: A Temporal Analysis from Time of Seroconversion (SC). J AIDS Clin Res 6: 523. doi:10.4172/21556113.1000523

a)
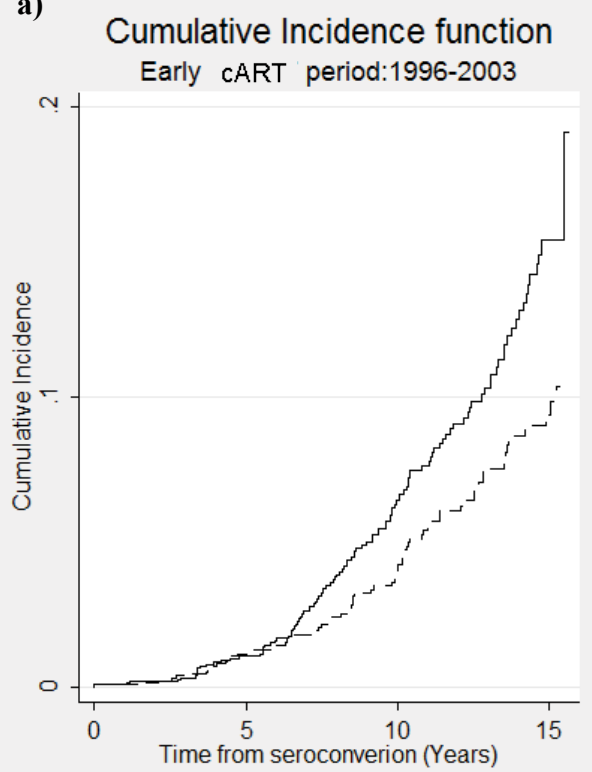

b)
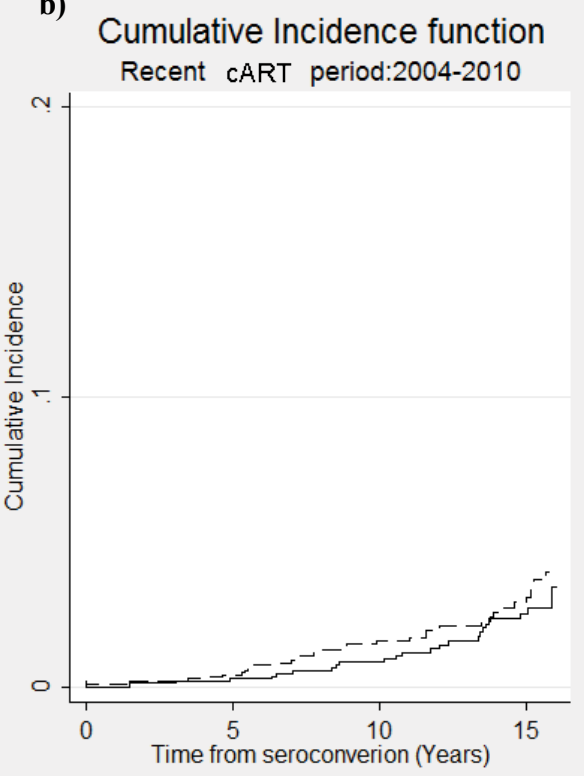

Non-AIDS related deaths

Figure 2: Cumulative incidence function (CIF) of AIDS- and non-AIDS-related deaths a) early cART (1996-2003) b) more recent cART period (2004-2010).

\section{Cox-cause-specific models for non-AIDS and AIDS deaths: (2004-2010) vs. (1996-2003)}

In Table 4 are shown RH of death relative to (2004-2010) vs. early calendar period (1996-2003) applying proportional-cause-specific regression models; all hazards of death resulted lower for recent cART period compared to the early cART period.

In particular, starting from SC the non-AIDS mortality decreased of nearly $62 \%$ (95\% CI: 44\%-74\%), whilst AIDS mortality was reduced by $70 \%$. Starting from a same age attained, the reduction of mortality was again less for non-AIDS than AIDS mortality: for instance, for those 45 yrs old we observed a reduction of 59\% in non-AIDS mortality, whilst for AIDS mortality we found a reduction of $43 \%$.

Even when considered the achievement of CD4 $>500$ cells $/ \mathrm{mm}^{3}$ or of a HIV-viral load (VL) $<200$ copies/mL), the reduction of non-AIDS death resulted not statistically significant and lower than that of AIDS death comparing the two calendar periods.

\section{Discussion}

Our findings suggest that both AIDS and non-AIDS mortalities in HIV-individuals with known date of seroconversion (SC) for HIV have further decreased from the early cART (1996-2003) to the more recent cART therapy period (2004-2010). At the same time, we found that non-AIDS- related mortality was slightly higher than AIDSrelated-mortality. These results were confirmed after controlling for similar duration of HIV-infection and effective cART. The reduction of mortality seemed to be observable for most causes of deaths, except for non-AIDS cancer, the rate of which did not change during the more recent CART years.

The results from many studies of HIV-seroprevalent populations have already shown elevated and continued reductions in AIDS-related

\begin{tabular}{|c|c|c|}
\hline & 1996-2003 (Ref.) & 2004-2010 \\
\hline & & RH $(95 \% \mathrm{Cl})$ \\
\hline \multicolumn{3}{|l|}{ AIDS-related-deaths } \\
\hline $\begin{array}{l}\text { RH from SC } \\
169 \text { events }\end{array}$ & & $0.30(0.20-0.45)$ \\
\hline $\begin{array}{l}\text { RH from cART } \\
129 \text { events }\end{array}$ & & $0.26(0.17-0.41)$ \\
\hline RH from age $\geq 45$ yrs & & $0.41(0.20-0.85)$ \\
\hline \multicolumn{3}{|l|}{28 events } \\
\hline $\begin{array}{l}\text { RH from last CD4 } \geq \mathbf{5 0 0 ( 2 )} \\
21 \text { events }\end{array}$ & & $0.38(0.18-0.80)$ \\
\hline $\begin{array}{l}\text { RH from last } \mathrm{VL}<200^{(2)} \\
31 \text { events }\end{array}$ & & $0.32(0.17-0.62)$ \\
\hline \multicolumn{3}{|l|}{ Non AIDS-related-deaths } \\
\hline $\begin{array}{l}\text { RH from SC } \\
109 \text { events }\end{array}$ & & $0.38(0.26-0.56)$ \\
\hline $\begin{array}{l}\text { RH from cART } \\
88 \text { events }\end{array}$ & & $0.34(0.23-0.51)$ \\
\hline $\begin{array}{l}\text { RH from age } \geq 45 \text { yrs } \\
28 \text { events }\end{array}$ & & $0.57(0.30-1.10)$ \\
\hline $\begin{array}{l}\text { RH from last CD4 } \geq 500 \text { (2) } \\
40 \text { events }\end{array}$ & & $0.69(0.38-1.27)$ \\
\hline $\begin{array}{l}\text { RH from last } \mathrm{VL}<200^{(2)} \\
42 \text { events }\end{array}$ & & $0.60(0.35-1.03)$ \\
\hline
\end{tabular}

${ }^{1}$ estimated by Cox cause-specific hazards model with the two grouped competing events (AIDS and non-AIDS related deaths); those who died from overdose were excluded; all models were stratified by HIV-exposure category and HCV-serostatus; estimates were performed accounting of delayed entries after 1996 from SC in all models.

${ }^{2}$ survival times were left-truncated from $\mathrm{SC}$ at the selected visit with alternatively achievement of start of CD4 $\geq 500$ cells $/ \mathrm{mm}^{3}$ or HIV-RNA $<200$ after start of cART; SC: HIV-seroconversion date estimated as central point between HIV-positive and negative tests (interval between tests not greater than 3 years).

Table 4: Relative Hazards (RHs) of non-AIDS and AIDS-related deaths of recent (2004-2010) vs. early cART period (1996-2003) applying competing risks models ${ }^{1}$. 
Citation: Dorrucci M, Colarusso L, Regine V, Giambenedetto SD, Perri GD, et al. (2015) Combined Antiretroviral Therapy (cART) Reduces AIDS-Related and Non-AIDS-Related Mortality: A Temporal Analysis from Time of Seroconversion (SC). J AIDS Clin Res 6: 523. doi:10.4172/21556113.1000523

Page 7 of 8

deaths over time, including into most recent time [7-9].

We observed a RH of AIDS-mortality equal to 0.30 and equal to 0.38 of non-AIDS mortality for the period 2004-2010 vs. 1996-2003 from the estimated HIV-SC. A direct comparison of this estimate with other studies could not be made because, to our knowledge, all other studies were not performed since the date of SC.

The observed decrease in mortality can be mainly explained with the increase of time (i.e., person-years) spent by individuals on cART therapy, given that it almost doubled from the earlier to the more recent cART period (from $48 \%$ to $86 \%$ of the time on follow-up, respectively). This is further confirmed by the finding that the RH estimated by Cox models decreased when the individual follow-up was considered since start of CART for both AIDS and non AIDS-related mortalities.

Other studies have been performed since the date of cART Smith et al. [7], for instance, estimated a significant decrease in the incidence ratio (IR) [IR $=0.63$ (95\% CI: $95 \%$ CI: $0.48-0.84$, relative to the 2009 2011 vs. the $1999-2000$ period]. The different estimates in our study may be due to the fact that in our seroincidence cohort the patients had most likely to start their therapy earlier than in seroprevalent studies $[1,8,9]$, where patients receive care when they are already HIV-positive.

Another reason for the pronounced decrease of mortality in our study could be the increase of CD4 cell counts in the studied population, as evidenced by the higher CD4 medians observed during the period 2003-2010, as well as the lower median HIV-load. This finding was also confirmed among those who reached a CD4 cell count greater than 500 cells $/ \mathrm{mm}^{3}$; in particular, the RH of AIDS-related deaths was $0.38(95 \%$ CI: $0.18-0.80$ ) from the last observed count $>500$, whereas the RH of non-AIDS-related deaths turned out to be almost close to unity.

In our study the cumulative incidence (CIF) of AIDS-related deaths resulted substantially higher than the CIF of non-AIDS-related deaths in the early cART period, whilst there was a reversal in the 2004-2010 periods: the CIF of non-AIDS-related deaths resulted slightly higher than that of AIDS-related deaths. This finding was confirmed in multiple analyses given that the adjusted IR of non AIDS related-deaths resulted higher than that of AIDS-related deaths. Again, this result was not directly comparable with other studies because of the different design and methodology.

The result that the non-AIDS death rate, as a whole, overlaps with the AIDS death rate in our study was possibly due to the increase observed in non-AIDS-related cancers when comparing the early cART to the more recent cART period. In fact, we observed a decreasing tendency of all other non-AIDS-specific causes of death, such as cardio-vascular or hepatitis-related or due to any other infections except for non-AIDS cancers. Other studies [7,8,17-23] observed a similar tendency from the start of cART. Smith et al., [7] in particular, found a statistically significant decrease of adjusted IR of both liver-related deaths and cardio-vascular deaths, but the adjusted IR of non-AIDS-cancers relative to recent CART years vs. early cART years always resulted nearly equal to unity, i.e., non-AIDS-related cancer rates have remained stable over time. These types of cancer seem now be the most common cause of non-AIDS death $[8,17]$.

An important caveat to this study is that, being observational in nature, we cannot rule out the possibility of unmeasured confounding. Although deaths were accurately classified, autopsy results were not available.

In conclusion, we observed a dramatic decrease in both AIDS- and non-AIDS-related mortalities when comparing the early with the more recent cART era. This seems to be mainly due to an improvement in the benefits of cART. At the same time, in more recent cART years the magnitude of non-AIDS mortality, considered as a whole, was close to that of AIDS mortality, even after controlling for duration of HIV infection and effective cART. A possible explanation is that non-AIDS cancers-related deaths tend not to decrease over time, suggesting that this field of research requires further study.

\section{Notes}

Statement of Funding: this study was supported by "Ministero della salute” (Ricerca Finalizzata 2009 code RF-2009-1505025).

Luca Colarusso (fully) and Rino Bellocco (partially) were funded by the Italian Ministry of Education (PRIN 2009X8YCBN).

\section{References}

1. Aldaz P, Moreno-Iribas C, Egues N, Irisarri F, Floristan Y, et al. (2011) Mortality by causes in HIV-infected adults: comparison with the general population. BMC Public Health 11: 300.

2. Simard EP, Pfeiffer RM, Engels EA (2012) Mortality due to cancer among people with AIDS: a novel approach using registry-linkage data and population attributable risk methods. AIDS 26: 1311- 1318.

3. Deeken JF, Tjen-A-Looi A, Rudek MA, Okuliar C, Young M, et al. (2012) The rising challenge of non-AIDS-defining cancers in HIV-infected patients. See comment in PubMed Commons below Clin Infect Dis 55: 1228-1235.

4. Hernandez MD, Sherman KE (2011) HIV/hepatitis C co-infection natural history and disease progression. Curr Opin HIV AIDS 6: 478-482.

5. Kirk GD, Mehta SH, Astemborski J, Galai N, Washington J, et al. (2013) HIV age, and the severity of hepatitis $C$ virus-related liver disease: a cohort study. See comment in PubMed Commons below Ann Intern Med 158: 658-666.

6. Falade-Nwulia O, Seaberg EC, Rinaldo CR, Badri S, Witt M, et al. (2012) Comparative risk of liver-related mortality from chronic hepatitis B versus chronic hepatitis C virus infection. Clin Infect Dis 55: 507-513.

7. Smith CJ, Ryom L, Weber R, Morlat P, Pradier C, et al. (2014) Trends in underlying causes of death in people with HIV from 1999 to 2011 (D:A:D): a multicohort collaboration. See comment in PubMed Commons below Lancet 384: 241-248.

8. Weber R, Ruppik M, Rickenbach M, Spoerri A, Furrer H, et al. (2012) Decreasing mortality and changing patterns of causes of death in the Swiss HIV Cohort Study. HIV Med 14:195-207.

9. Helleberg M, Kronborg G, Larsen CS, Pedersen G, Pedersen C, et al. (2012) Causes of death among Danish HIV patients compared with population controls in the period 1995-2008. See comment in PubMed Commons below Infection 40: $627-634$

10. Rezza G, Lazzarin A, Angarano G, Sinicco A, Pristerà R, et al. (1989) The natural history of HIV infection in intravenous drug users: risk of disease progression in a cohort of seroconverters. AIDS 3: 87-90.

11. Dorrucci M, Phillips AN, Longo B, Rezza G and the Italian Seroconversion Study (2005) Changes over time in post-seroconversion CD4 cell counts in the Italian HIV-Seroconversion Study: 1985-2002. AIDS 19: 331-335.

12. Camoni L, Boros S, Regine V, Santaquilani M, Ferri M, et al. (2014) Aggiornamento delle nuove diagnosi di infezione da HIV e dei casi di AIDS in Italia al 31 dicembre 2013. Not Ist Super Sanità 27: 3-47. (Italian)

13. Barua A, Kar N (2010) Screening for depression in elderly Indian population. See comment in PubMed Commons below Indian J Psychiatry 52: 150-153.

14. Klein J (2010) Competing Risks. Wiley Interdisciplinary Reviews: Computational Statistics 3: 333-339.

15. Wada N, Jacobson LP, Cohen M, French Audrey, Phair J, et al. (2013) CauseSpecific Life Expectancies After 35 Years of Age for Human Immunodeficiency Syndrome-Infected and Human Immunodeficiency Syndrome-Negative Individuals Followed Simultaneously in Long-term Cohort Studies, 1984-2008. Am J Epidemiol 177: 116-125

16. Reekie J, Gatell JM, Yust I, Bakowska E, Rakhmanova A, et al. (2011) Fatal and nonfatal AIDS and non-AIDS events in HIV-1-positive individuals with high CD4 
Citation: Dorrucci M, Colarusso L, Regine V, Giambenedetto SD, Perri GD, et al. (2015) Combined Antiretroviral Therapy (cART) Reduces AIDS-Related and Non-AIDS-Related Mortality: A Temporal Analysis from Time of Seroconversion (SC). J AIDS Clin Res 6: 523. doi:10.4172/21556113.1000523

Page 8 of 8

cell counts according to viral load strata. See comment in PubMed Commons below AIDS 25: 2259-2268.

17. Simard EP, Pfeiffer RM, Engels EA (2012) Mortality due to cancer among people with AIDS: a novel approach using registry-linkage data and population attributable risk methods. See comment in PubMed Commons below AIDS 26 $1311-1318$.

18. Leone S, Gregis G, Quinzan G, Velenti D, Cologni G, et al. (2011) Causes of death and risk factors among HIV-infected persons in the HAART era: analysis of a large urban cohort. See comment in PubMed Commons below Infection 39: $13-20$

19. Galli L, Spagnuolo V, Salpietro S, Gianotti N, Cossarini F, et al. (2012) Mortality of HIV-infected patients with or without cancer: comparison with the general population in Italy. Antivir Ther 17: 447-458.

20. Aldaz P, Moreno-Iribas C, Egüés N, Irisarri F, Floristan Y, et al. (2011) Mortality by causes in HIV-infected adults: comparison with the general population. See comment in PubMed Commons below BMC Public Health 11: 300.

21. Lohse N, Gerstoft J, Kronborg G, Larsen CS, Pedersen C, et al. (2011) Comorbidity acquired before HIV diagnosis and mortality in persons infected and uninfected with HIV: a Danish population-based cohort study. See comment in PubMed Commons below J Acquir Immune Defic Syndr 57: 334-339.

22. Antiretroviral Therapy Cohort Collaboration (2010) Causes of death in HIV-1 infected patients treated with antiretroviral therapy, 1996-2006: collaborative analysis of 13 HIV cohort studies. See comment in PubMed Commons below Clin Infect Dis 50: 1387-1396.

23. Mocroft A, Soriano V, Rockstroh J, Reiss P, Kirk O, et al. (2005) Is there evidence for an increase in the death rate from liver-related disease in patients with HIV? AIDS 19: 2117-2125.

Appendix - ISS study:

Adriano Lazzarin e Antonella Castagna, Ospedale San Raffaele, Milano;

Gioacchino Angarano, Policlinico, Bari;

Simona Digiambenedetto, Università Cattolica S. Cuore, Istituto Malattie Infettive, Roma;

Raffaele Pristerà, Ospedale Regionale, Divisione Malattie Infettive, Bolzano;

Emanuela Vaccher, Centro Riferimento Oncologico, Aviano;

Maria Alessandra Ursitti, Arcispedale S. Maria Nuova, Reggio Emilia;

Giovanni di Perri, Ospedale Amedeo di Savoia, Torino;

Vincenzo Colangeli, Università degli Studi, Bologna;

Ivano Mezzaroma, Università La Sapienza, Roma;

Francesco Castelli, Spedali Civili, Brescia;

Guido Palamara, Ospedale S. Gallicano, Roma;

Mauro Zaccarelli, Ospedale Spallanzani, Roma;

Francesco Alberici, Ospedale Civile, Piacenza;

Massimo Galli, Università degli studi, Milano. 